\title{
Perioperative interstitial CT-based brachytherapy boost in breast cancer patients with breast conservation after neoadjuvant chemotherapy
}

\author{
M. DOLEZEL ${ }^{1,4, *}$, K. STASTNY², K. ODRAZKA ${ }^{1,4,5}$, J. VANASEK ${ }^{1}$, T. KOHLOVA ${ }^{3}$, D. DVORAKOVA ${ }^{1}$, I. KOLAROVA ${ }^{1}$, T. KROULIK ${ }^{1}$, L. JALCOVA ${ }^{1}$ \\ ${ }^{1}$ Oncology Centre, Multiscan \& Pardubice Regional Hospital, Pardubice, Czech Republic; ${ }^{2}$ Department of Surgery, Pardubice Regional \\ Hospital, Pardubice, Czech Republic; ${ }^{3}$ Department of Nuclear Medicine, University Hospital Hradec Kralove, Czech Republic; ${ }^{4}$ First Faculty \\ of Medicine, Charles University in Prague, Prague, Czech Republic; ${ }^{5}$ Third Faculty of Medicine, Charles University in Prague, Prague, \\ Czech Republic
}

${ }^{*}$ Correspondence: dolezelm@email.cz

Received November 10, 2011 / Accepted March 19, 2012

\begin{abstract}
Intraoperative placement of catheters in the tumor bed during breast-conserving surgery (BCS) enables postponed targeted boost irradiation in high risk breast cancer patients. Twenty-three patients with high risk breast cancer underwent neoadjuvant chemotherapy and multifractionated perioperative brachytherapy as a boost to the tumor bed using threedimensional (3D) CT-based planning. Plastic catheters for brachytherapy were implanted during surgery and targeted irradiation was delivered in the course of 2-3 weeks. Acute and late toxicities were scored according to the RTOG Common Toxicity Criteria. Cosmetic outcomes were assessed using the Harvard criteria. No major perioperative complications were recorded. Circumscribed wound infection occurred in one patient (4.3\%). Only 3 patients (13\%) experienced acute skin toxicity Grade 1. We observed no teleangiectasias or pigmentations. The cosmetic outcome at last follow-up visit was rated as excellent/good, in $82.6 \%$, fair, in $13 \%$ and poor in $4.4 \%$ of patients, respectively. There was no evidence of disease recurrence after median follow-up of 43. 4 months. Systematic integration of the perioperative fractionated 3D CT-based HDR brachytherapy as a boost for patients with breast cancer after BCS is feasible and seems safe. It might be beneficial especially for women with high risk of local recurrence.
\end{abstract}

Key words: brachytherapy, boost, breast cancer, intraoperative radiotherapy, local control, target volume

Several randomized clinical trials have shown equivalent results after breast-conserving therapy (BCT) and mastectomy in stage I and II breast cancer [1-4]. The meta-analysis of the Early Breast Cancer Trialists 'Collaborative Group (EBCTCG) confirmed the equivalence of those two approaches with survival as endpoint and the need for radiotherapy following lumpectomy to reduce the 5-year local recurrence rate from $26 \%$ to $7 \%$ [5]. Local recurrences are known to occur predominantly at the primary tumor site or its immediate vicinity. An improvement in local control rates has been reported with increasing dose in retrospective as well as prospective randomized studies. Conventional target volume for adjuvant radiotherapy in patients undergoing breast-conserving therapy is the whole breast (and regional lymphatics in selected cases) with a boost dose to the tumor bed.

The prospective randomized Lyon trial proved a significant effect of $10 \mathrm{~Gy}$ electron boost on local recurrence rate after five years [6]. In the European Organization on Research and Treatment of Cancer (EORTC) „,boost versus no boost“ trial (2281/10882), a highly significant reduction in the local recurrence rate after five years has been shown in the patient group with a boost compared to no boost group. Greater absolute reduction of local failure was observed in younger patients [7].

The boost dose can be delivered by external beam radiotherapy (EBRT) using photons and electrons or by brachytherapy. Brachytherapy can deliver very high dose in a short period of time. An essential feature of the brachytherapy implant is the rapid dose fall off around the radioactive sources. As a result, better dose distribution can be achieved in comparison with the external beam boost. Smaller volumes of the irradiated breast tissue and lower dose to the skin blood vessels are evident especially in deeply seated tumors. In case of postoperative brachytherapy, the accurate insertion of 
a)

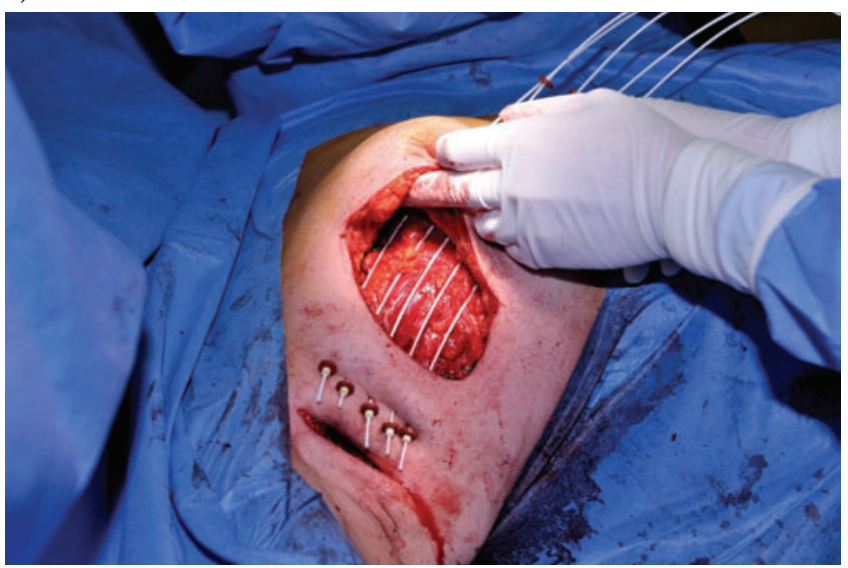

b)

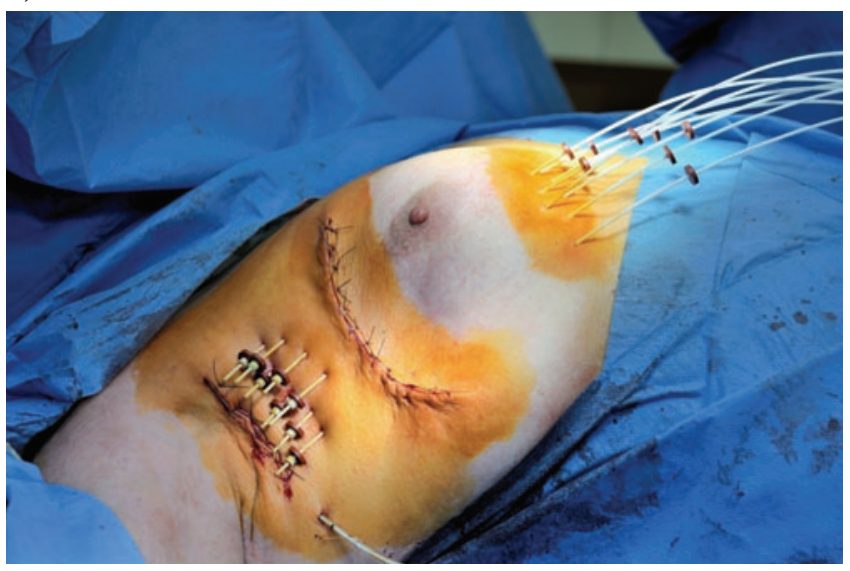

Figure 1a) Perioperative insertion of plastic afterloading catheters into the tumor bed. 1 b) Plastic afterloading catheters after closure of the surgical wound.

needles into the tumor bed is sometimes technically difficult, especially when clips are lacking. There is a large experience with brachytherapy in postoperative setting using low dose rate (LDR) implants but limited with brachytherapy using high dose rate (HDR) stepping-source. Stepping-source design permits excellent control of the source position through the target volume. The HDR remote afterloader enables to perform accelerated partial breast brachytherapy using MammoSite in low risk patients but also intraoperative accurate placement of catheters for subsequent multifractionated postoperative radiation in high risk patients. The use of polyethylene applicators allows postponed three-dimensional (3D) CT-based planning with knowledge of the pathological status of the tumor margin and the presence of high risk factors. Three-dimensional planning also enables to optimize the dose distribution with skin sparing.

In patients with high risk of local recurrence, the perioperative application of afterloading catheters into the tumor bed during breast conserving surgery was incorporated into our clinical practice. To our knowledge, no systematic integration of perioperative fractionated 3D CT-based HDR brachytherapy as a boost has previously been published. This study aims to evaluate the feasibility of perioperative applicator insertion, and to determine the early results.

\section{Patients and Methods}

Patients and treatment. Perioperative brachytherapy was used in 23 patients with high risk T2 N0-1 M0 tumors where the neoadjuvant chemotherapy was necessary before breast-conserving surgery. All patients underwent marking of the tumor borders using four blue dye tattoos before the start of neoadjuvant chemotherapy. During breast-conservative surgery (after excision of supposed residual tumor), afterloading polyethylene applicators were inserted into the tumor bed in one or more planes according to tumor topography (GammaMed Interstitial

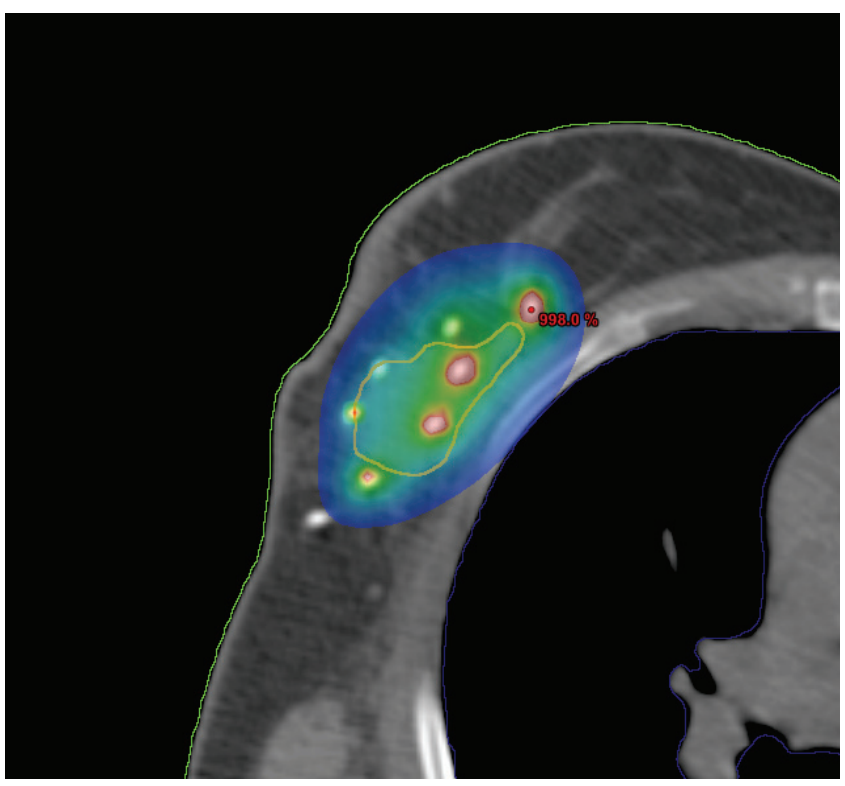

Figure 2. Dose distribution of 3D CT-based plan (tumor bed is contoured by yellow line, prescribed dose covers tumor bed with a $10 \mathrm{~mm}$ margin, skin and lung sparing is apparent).

applicators, Varian Medical Systems, USA). The implant covered tumor bed with a margin of at least $15 \mathrm{~mm}$. The implant geometry was designed in agreement with the Paris System rules. The catheters were implanted parallel and equally distant from each other, usually spaced $10-15 \mathrm{~mm}$. If two or more planes were implanted, catheters were disposed either in a triangle or a square pattern (Figure 1a, 1b). The resected tumor tissue was marked by three coloured stitches to enable the targeted dose escalation in case of close margins.

During the second/third week after surgery, the planning CT scans were taken with a slice thickness of $3 \mathrm{~mm}$. Images 
Table 1. Patient and tumor characteristics.

\begin{tabular}{lc}
\hline Variable Mean (range) & \\
\hline Age (year) & $36(34-59)$ \\
Clinical tumor size (cm) & $1.9(0-1-4.8)$ \\
Pathological tumor size (cm) & \\
Clinical lymph node status & 82.6 \\
$\quad$ Positive (\%) & \\
Pathological lymph node status & 43.5 \\
$\quad$ Positive (\%) & \\
Grade & 0 \\
$\quad$ G1 (\%) & 52.2 \\
$\quad$ G2 (\%) & 47.8 \\
$\quad$ G3 (\%) & \\
Hormone receptors & $27(0-80)$ \\
$\quad$ Positive for estrogen (\%) & $32(0-90)$ \\
$\quad$ Positive for progesteron (\%) & \\
HER2/neu amplification & 13 \\
$\quad$ Positive (\%) & $35(10-90)$ \\
Ki67 (\% positive) & 39.1 \\
Extensive intraductal component (\%) & \\
Final margin status & 0 \\
$\quad$ Positive (\%) & Negative (\%) \\
Neoadjuvant chemotherapy (\%) & 100 \\
Axillary dissection(\%) & $100 \%$ \\
\hline
\end{tabular}

Table 2. Treatment characteristics

\begin{tabular}{lc}
\hline Variable Mean (range) & \\
Interval between implantation and treatment (days) & $13(11-19)$ \\
Excision volume (cm3) & $254(35-498)$ \\
Needle spacing $(\mathrm{cm})$ & $1.3(0.8-1.8)$ \\
Number of catheters (median) & $7.1(6-10)$ \\
Implant & 17.4 \\
$\quad$ Single plane (\%) & 82.6 \\
$\quad$ Double plane $(\%)$ & \\
V100 (cm3) & $88.7(29-107)$ \\
V150 (cm3) & $25.9(7.9-37)$ \\
DHI & $0.71(0.66-0.81)$ \\
\hline
\end{tabular}

Abbreviations: $V 100=$ volume covered by prescribed dose, $V 150=$ volume receiving more than $150 \%$ of the prescribed dose, $D H I=$ dose homogeneity index

were transferred to the treatment planning system (BrachyVision, Varian Medical Systems, USA). Using a CT-based three dimensional software the catheters were indentified in three orthogonal planes reconstructed from CT data. The dwell spacing in all cases was fixed at $3 \mathrm{~mm}$. Contouring of the target volume was initiated with the surgical cavity delineation on each CT slice.

Subsequently, the clinical target volume (CTV) was defined by a rim of 10-15 $\mathrm{mm}$ of normal breast tissue surrounding the cavity with a respect to the pathological status of tumor margin. The prescribed dose was $12 \mathrm{~Gy}$ in four fractions bid (two fractions per day) with a 12-hour interval between two treatments. Sparing of the healthy tissues (skin, lung) was possible using the 3D CT-based planning (Figure 2). The dose homogeneity index was used to assess the implant quality [8]. Irradiation with fractionated brachytherapy was started between days 11 and 19 (median day 13) after surgery using the Iridium 192 HDR afterloading machine (GammaMedplus, Varian Medical Systems, USA). The plastic catheters were extracted after finishing the boost treatment. In one week from the end of brachytherapy, patients started irradiation of the whole breast with or without regional lymphatics. Prescribed dose for external beam radiotherapy was $48.6 \mathrm{~Gy}$ in 27 fractions, five fractions per week. All patients gave their informed consent in writing with regard to both the purpose and protocol of the study.

Toxicity and local control. All patients were continuously followed during and after treatment. They were scheduled to be seen by radiation oncologist and surgeon every week during radiotherapy, one month after the end of the irradiation treatment, every three months for the first two years, and every six months thereafter.

Acute and late toxicity symptoms were scored based on the Radiation Therapy Oncology Group (RTOG) Common Toxicity Criteria. Cosmetic results were evaluated at each follow-up visit by the radiation oncologist or surgeon using Harvard criteria [9]. An excellent cosmetic result score was assigned when the treated breast looked essentially the same as the contralateral breast (as related to radiation effects). A good cosmetic score was assigned for minimal but identifiable radiation effects of the treated brest. A fair score was used for significant radiation effects. A poor score meant severe sequelae of breast tissue, secondary to radiation.

In order to assess local control, physical examination was performed at each follow-up visit and mammograms were obtained 6 months after treatment and annually thereafter.

\section{Results}

The clinical and therapy-related features of the patients are listed in Tables 1 and 2. The median follow-up was 43.4 months. Perioperative insertion of the applicators was succesful in all 23 patients. The average time of insertion of the applicators was 15 minutes. The tolerance of catheter placement and irradiation was excelent. We did not observe any severe periprocedural complications. Circumscribed wound infection occurred in one patient $(4.3 \%)$ and it was treated with oral antibiotics. We observed no inflammatory reaction nor pathological changes in laboratory tests (including blood count). No patient experienced acute skin toxicity greater than Grade 1. Slight transient erythema was seen in 3 out of 23 patients (13\%). Erythema disappeared in all patients within few hours.

We observed no teleangiectasias or pigmentations. One patient suffered from persisted seroma with temporary seroma leak before irradiation and repeated punctures were necessary after the end of radiotherapy. After three months, seroma healed without consecutive late toxicity. 
The cosmetic outcome at last follow-up visit was rated as excellent/good in $19(82.6 \%)$, fair in three (13\%), and poor in one $(4.4 \%)$ patients, respectively. To date, no disease recurrence has been detected.

\section{Discussion}

A boost dose to the breast tumor bed can be delivered by external beam radiotherapy (EBRT) or interstitial brachytherapy.

A large European randomised trial (EORTC 22881/10882) investigated the delivery of higher localised radiation dose using the external beam technique and LDR interstitial brachytherapy to the tumor bed following conservative surgery for early breast cancer. The 5-year local recurrence rate was 4.7 $\%$ for electron boost, $4 \%$ for photon boost and only $2.5 \%$ for interstitial brachytherapy boost. The differences were not statistically significant, possibly due to lower number of events and patients in the interstitial group [10].

When EBRT is carried out, haemoclips can help to localise the target area using conventional or CT-simulator [11]. Nevertheless, the postoperative changes and tissue remodelling make sometimes the localization of the tumor bed difficult [12, $13,14]$. Postoperative seroma edges and corresponding clips do not always match well. Seroma edges extend beyond clips by an average of 3-5 $\mathrm{mm}$ and nearly a quarter of the margines have a gap between clips and seroma edges exceeding $5 \mathrm{~mm}$ [15]. This uncertainity causes significant interobserver variability in the delineation of the clinical target volume (CTV) for boost even among radiation oncologists who specialize in breast radiotherapy [16]. Therefore the use of CT-based volume delineation for external beam radiotherapy results in a larger irradiated boost volume [17]. This larger boost volume may however unnecessarily increase the risk of side effects especially with a higher boost dose [18-21].

Perioperative radiotherapy has been successfully introduced for several anatomic sites [22-25]. Application of catheters for HDR brachytherapy during breast-conserving surgery allows direct visualization to the target volume and its appropriate covering by the implant. This fundamental advantage could result in smaller implant volume and consequently in less fibrosis [20, 26, 27]. Moreover, a more precise localization of the target volume may improve local control. Certain potential drawbacks of the HDR breast brachytherapy must be considered regarding treatment timing and fractionation. Starting irradiation immediately or too soon after surgery could likely have a negative impact on wound healing leading to more fibrosis and worse cosmetics [28]. Also a single large HDR dose may cause permanent damage of the surrounding healthy tissues leading to severe toxicity. Because the late effects are reduced with decreasing the dose per fraction, the fractionation of the total dose with postponed irradiation can improve the cosmetic results without reducing the local control. Utilization of the 3D CT-based brachytherapy can decrease the mean skin dose, reduce the risk of geographical miss, and achieve better conformity between planning target volume and treated volume [29].

Therefore we incorporated in our clinical practice the perioperative application of afterloading catheters into tumor bed during breast conserving surgery with postponed fractionated irradiation using 3D CT-based HDR brachytherapy planning.

Our preliminary results are very promising. We observed no local or distant relapse. Although the average surgical excised volume in our study was larger than in most published studies, supposedly due to higher clinical stage, the volume irradiated in our patients with prescribed dose was substantially smaller [20, 28]. Three-dimensional brachytherapy CT-based planning enabled among other things also optimization with reduction of the dose to the skin. We are convinced that this is the main reason for the absence of late skin toxicity. Using the polyethylene applicators made possible to delay the start of fractionated irradiation until the wound had been healed up. Furthermore, the information about the pathological status of the tumor margin and the presence/absence of high risk factors allowed better treatment plan optimization. Longer follow-up is needed to confirm these promising early results.

\section{Conclusion}

This study brings yet unpublished evidence of the systematic integration of perioperative fractionated 3D CT-based HDR brachytherapy as a boost for patients with early breast cancer after breast-conserving surgery. Our experience suggests that this technique is feasible and seems safe. It might be beneficial especially for women with high risk of local recurrence.

\section{References}

[1] FISHER B, ANDERSON S, BRYANT J, MARGOLESE RG, DEUTSCH $\mathrm{M}$ et al. Twenty-year follow-up of a randomized trial comparing total mastectomy, lumpectomy, and lumpectomy plus irradiation for the treatment of invasive breast cancer. N Engl J Med 2002; 347: 1233-1241. http://dx.doi. org/10.1056/NEJMoa022152

[2] SARRAZIN D, LE MG, ARRIGADA R, CONTESSO G, FONTAINE $\mathrm{F}$ et al. Ten-year results of a randomized trial comparing a conservative treatment to mastectomy in early breast cancer. Radiother Oncol 1989; 14: 177-184. http:// dx.doi.org/10.1016/0167-8140(89)90165-5

[3] VAN DONGEN JA, VOOGD AC, FENTIMAN IS, LEGRAND C, SYLVESTER RJ et al. Long-term results of a randomized trial comparing breast-conserving therapy with mastectomy: European Organization for Research and Treatment of Cancer 10801 trial. J Natl Cancer Inst 2000; 92: 1143-1150. http:// dx.doi.org/10.1093/jnci/92.14.1143

[4] VERONESI U, CASCINELLI N, MARIANI L, GRECO M, SACCOZZI R et al. Twenty-year follow-up of a randomized study comparing breast-conserving surgery with radical 
mastectomy for early breast cancer. N Engl J Med 2002; 347: 1227-1232. http://dx.doi.org/10.1056/NEJMoa020989

[5] EARLY BREAST CANCER TRIALISTS' COLLABORATIVE GROUP (EBCTCG). Effects of radiotherapy and of differences in the extent of surgery for early breast cancer on local recurrence and 15-year survival: an overview of the randomized trials. Lancet 2005; 366: 2087-2106.

[6] ROMESTAING P, LEHINGUE Y, CARRIE C, COGUARD $\mathrm{R}$, MONTBARBON X et al. Role of a 10-Gy boost in the conservative treatment of early breast cancer: results of a randomized clinical trial in Lyons, France. J Clin Oncol 1997; 15: 963-968.

[7] ANTONINI N, JONES H, HORIOT JC, POORTMANS P, STRUIKMANS $\mathrm{H}$ et al. Effect of age and radiation dose on local control after breast conserving treatment: EORTC trial 2281-10882. Radiother Oncol 2007; 82: 265-271. http:// dx.doi.org/10.1016/j.radonc.2006.09.014

[8] WU A, ULIN K, STERNICK ES. A dose homogeneity index for evaluating Ir-192 interstitial breast implants. Med Phys 1988;15:104-107. http://dx.doi.org/10.1118/1.596152

[9] ROSE AM, OLIVOTTO I, CADY B, KOUFMAN C, OSTEEN $\mathrm{R}$ et al. Conservative surgery and radiation therapy for early breast cancer. Long-term cosmetic results. Arch Surg 1989; 123: 679-689.

[10] POORTMANS P, BARTELINK H, HORIOT JC, STRUIKMANS H, VAN DEN BOGAERT W et al. The influence of the boost technique on local control in breast conserving treatment in the EORTC 'boost versus no boost' randomised trial. Radiother Oncol 2004; 72: 25-33. http://dx.doi.org/10.1016/ j.radonc.2004.03.007

[11] COLES CE, WILSON CB, CUMMING J, BENSON JR, FOROUHI $\mathrm{P}$ et al. Titanium clip placement to allow accurate tumour bed localisation following breast conserving surgery: audit on behalf of the IMPORT Trial Management Group. Eur J Surg Oncol 2009; 35: 578-582. http://dx.doi.org/10.1016/ j.ejso.2008.09.005

[12] OH KS, KONG FM, GRIFFITH KA, YANKE B, PIERCE LJ. Planning the breast bed boost: changes in the excision cavity volume and surgical scar location after breast-conserving surgery and whole-breast irradiation. Int J Radiat Oncol Biol Phys 2007; 66: 680-686.

[13] JACOBSON G, BETTS V, SMITH B. Change in volume of lumpectomy cavity during external-beam irradiation of the intact breast. Int J Radiat Oncol Biol Phys 2006; 65: 1161-1164. http://dx.doi.org/10.1016/j.ijrobp.2006.02.009

[14] KIROVA YM, FOURNIER-BIDOZ N, SERVOIS V, LAKI F, POLLET GA et al. How to boost the breast tumor bed? A multidisciplinary approach in eight steps. Int J Radiat Oncol Biol Phys 2008; 72: 494-500. http://dx.doi.org/10.1016/ j.ijrobp.2007.12.059

[15] YANG Z, CHEN J, HU W, PAN Z, CAI G et al. Planning the breast boost: how accurately do surgical clips represent the CT seroma? Radiother Oncol 2010; 97: 530-534. http://dx.doi. org/10.1016/j.radonc.2010.09.007

[16] LANDIS DM, LUO W, SONG J, BELLON JR, PUNGLIA RS et al. Variability among breast radiation oncologists in delineation of the postsurgical lumpectomy cavity. Int J
Radiat Oncol Biol Phys 2007; 67: 1299-1308. http://dx.doi. org/10.1016/j.ijrobp.2006.11.026

[17] HANBEUKERS B, BORGER J, VAN DEN ENDE P, VAN DER ENT F, HOUBEN R et al. Customized computed tomography-based boost volumes in breast-conserving therapy: use of three-dimensional histologic information for clinical target volume margins. Int J Radiat Oncol Biol Phys 2009; 75: 757-763. http://dx.doi.org/10.1016/j.ijrobp.2008.11.048

[18] BARTELINK H, HORIOT JC, POORTMANS P, STRUIKMANS H, VAN DEN BOGAERT W et al. Impact of a higher radiation dose on local control and survival in breast-conserving therapy of early breast cancer: 10-year results of randomized boost versus no boost EORTC 22881-10882 trial. J Clin Oncol 2007; 25: 3259-3265. http://dx.doi.org/10.1200/ LCO.2007.11.4991

[19] VRIELING C, COLLETTE L, FOURQUET A, HOOGENRAAD WJ, HORIOT JC et al. The influence of the boost in breastconserving therapy on cosmetic outcome in the EORTC "boost versus no boost" trial. Int J Radiat Oncol Biol Phys 1999; 45: 677-685. http://dx.doi.org/10.1016/S0360-3016(99)00211-4

[20] VRIELING C, COLLETTE L, FOURQUET A, HOOGENRAAD WJ, HORIOT JC et al. The influence of patient, tumor and treatment factors on the cosmetic results after breastconserving therapy in the EORTC ,boost vs. no boost' trial. Radiother Oncol 2000; 55: 219-232.http://dx.doi.org/10.1016/ S0167-8140(00)00210-3

[21] NEUMANNOVA R, PETERA J, FRGALA T, DUSEK L, JARKOVSKY J et al.Long-term outcome with interstitial brachytherapy boost in the treatment of women with earlystage breast cancer. Neoplasma. 2007; 54(5): 413-423.

[22] VAIDYA JS, BAUM M, TOBIAS JS, MORGAN S, D’SOUZA $D$. The novel technique of delivering targeted intraoperative radiotherapy (Targit) for early breast cancer. Eur J Surg Oncol 2002; 28: 447-454. http://dx.doi.org/10.1053/ejso.2002.1275

[23] PETERA J, NEUMANNOVA R, ODRAZKA K, ONDRAK M, SOUMAROVA R et al. Perioperative fractionated high-dose rate brachytherapy in the treatment of soft tissue sarcomas. Neoplasma. 2004; 51(1): 59-63.

[24] SLAMPA P, SOUMAROVA R, RUZICKOVA J, CHRENKO V, FAIT V et al. Pilot study of sole conformal peroperative interstitial brachyradiotherapy of early stage breast carcinoma using high-dose rate afterloading. Neoplasma. 2005; 52(4): 292-296.

[25] KALLINOWSKI F, EBLE MJ, BUHR HJ, WANNENMACHER $\mathrm{M}, \mathrm{HERFATH} \mathrm{C}$. Intraoperative radiotherapy for primary and recurrent rectal cancer. Eur J Surg Oncol 1995; 21: 191-194. http://dx.doi.org/10.1016/S0748-7983(95)90501-4

[26] BORGER JH, KEMPERMAN H, SMITT HS, HART A, VAN DONGEN J et al. Dose and volume effects on fibrosis after breast conservation therapy. Int J Radiat Oncol Biol Phys 1994; 30: 1073-1081. http://dx.doi.org/10.1016/03603016(94)90312-3

[27] OLIVOTTO IA, ROSE MA, OSTEEN RT, LOVE S, CADY $B$ et al. Late cosmetic outcome after conservative surgery and radiotherapy: analysis of causes of cosmetic failure. Int J Radiat Oncol Biol Phys 1989; 17: 747-753. http://dx.doi. org/10.1016/0360-3016(89)90061-8 
[28] PIETERSBR, HART AAM, RUSSELLNS, JANSENEP, PETERSE JL et al. A comparison in cosmetic outcome between per-operative interstitial breast implants and delayed interstitial implants after external beam radiotherapy. Radiother Oncol 2003; 67: 159-164. http://dx.doi.org/10.1016/S0167-8140(03)00034-3
[29] POLGAR C, SOMOGYI A, TAKACSI-NAGY Z, MANGEL LC, FORRAI G et al. CT-image-based conformal brachytherapy of breast cancer. The signifikance of semi-3-D and 3-D treatment planning. Strahlenther Onkol 2000; 176: 118-124. http://dx.doi.org/10.1007/PL00002336 